\title{
HACIA UN CONCEPTO DE PAZ EN COLOMBIA ${ }^{1}$
}

\author{
Katherine Hernández Tirado ${ }^{2}$ \\ Daniela María Orozco Poveda ${ }^{3}$
}

\begin{abstract}
Resumen
Por las particularidades del conflicto interno la conceptualización de la paz en Colombia ha estado enmarcado en negociaciones y acuerdos políticos, sin embargo, su estudio debe estructurarse desde los antecedentes históricos que sobre el concepto se han realizado; por ello este trabajo se centrará en pensar el concepto de paz en Colombia desde un punto de vista teórico y jurisprudencial.
\end{abstract}

Palabras Clave: Paz, Colombia, concepto, jurisprudencia.

\begin{abstract}
Due to the particularities of the internal conflict, the conceptualization of peace in Colombia has been framed in negotiations and political agreements, however, its study must be structured from the historical antecedents that have been made about the concept; for this reason, this work will focus on thinking about the concept of peace in Colombia from a theoretical and jurisprudential point of view.
\end{abstract}

Keywords: Peace, Colombia, concept, jurisprudence.

1 Este trabajo es resultado del proyecto de investigación denominado: "Ideas de paz de las asociaciones de víctimas del conflicto armado en Montería”, financiado por la Universidad Pontificia Bolivariana Seccional Montería.

2 Abogada, Universidad de Medellín. Magister en Gobierno, Universidad de Medellín, Docente investigador del Grupo COEDU de la Universidad Pontificia Bolivariana Seccional Montería. ORCID ID: https://orcid.org/0000-0001-5524-6575 Correo electrónico: katerine.hernandez@upb.edu.co

${ }^{3}$ Abogada, Universidad Pontificia Bolivariana Seccional Montería. Magister (C) Derecho, Universidad de Medellín. Docente investigador del Grupo COEDU de la Universidad Pontificia Bolivariana Seccional Montería. ORCID ID: https://orcid.org/0000-0003-46274608 Correo electrónico: daniela.orozcop@upb.edu.co 


\section{Introducción}

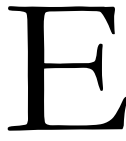

n Colombia ha sido recurrente la palabra paz, esta ha estado en el argot de la comunidad nacional e internacional a razón del conflicto interno y la diversidad de sucesos violentos, la paz se ha asociado a una diversidad de sucesos que han dado lugar a la creación de grupos insurgentes, paraestatales y la violencia sistemática.

El interés sobre la paz surge desde el momento en que se aceptó que la violencia desencadeno el conflicto armado que tenía como actores al Estado y diferentes grupos insurgentes, estos hechos generaran el interés por iniciar diferentes procesos de paz.

La paz debe pensarse mucho más allá de negociaciones y acuerdos políticos, esta requiere que se estructure desde los contextos y discusiones que sobre su concepto se ha dado, este trabajo parte en un primer momento por evidenciar los hechos que dieron lugar a una discusión sobre la paz, en un segundo momento a la presentación de las diferentes conceptos de paz partiendo del concepto de paz perpetua de Abbé de Saint -Pierre de 1713 hasta el de paz neutra de Francisco Jiménez Bautista en 2014 para terminar con un tercer momento con la evolución del concepto de paz en la Corte Constitucional.

No existe un concepto unificado de paz en Colombia, el concepto más cercano es el de Paz Neutra que recoge los pilares del Acuerdo Final entre las FARC-EP y el gobierno Colombiano firmado en el 2016 con los preceptos de la Corte Constitucional.

\section{E1 proceso en Colombia para entender la paz}

La paz ha sido un tema recurrente a lo largo de la historia, en el caso de Colombia este concepto se convirtió en aspecto central del discurso político desde mediados del siglo XX, cuando en 1948 durante los hechos conocidos como el Bogotazo se da el asesinato del aspirante presidencial Jorge Eliécer Gaitán, desenfrenando una guerra bipartidista entre los Liberales y los Conservadores, conflicto que deja como resultado la muerte de miles de ciudadanos, a razón de estos hechos es posible hablar del surgimiento del conflicto armado en Colombia. 
Con posterioridad durante el periodo comprendido entre 1958 a 1982, la violencia pasa de ser de una violencia bipartidista a una violencia subversiva, con la conformación de las Fuerzas Armadas Revolucionarias de Colombia- FARC-EP, el Ejército de Liberación Nacional- ELN y el Movimiento 19 de abril- M-19, entre otros y durante los años 1982 a 1996, se caracteriza por la expansión territorial, el crecimiento militar y la proyección política de las guerrillas, la época de los grandes carteles del narcotráfico, Medellín y Cali, la nueva Constitución Política de 1991 y el primer fallido diálogo de paz entre las FARC y el ELN durante el gobierno del expresidente Belisario Betancur, desencadenando la creación de los grupos de autodefensa como una manera de proteger a la población frente a los constantes ataques guerrilleros (Arias, Camacho, Ibañez, Mejia, \& Rodríguez, 2014).

Durante los primeros cinco años del siglo XXI en Colombia se da el fortalecimiento de las guerrillas, los grupos paramilitares y la lucha contra los carteles del narcotráfico, se da nuevamente un acercamiento entre el gobierno y los grupos al margen de la ley, FARC-EP, dando lugar a una zona de despeje, durante los diálogos de paz con el expresidente Andrés Pastrana sin embargo, no dieron una respuesta positiva sino que permitió que las FARC reorganizaran su estructura militar y fortalecieran la producción de cultivos ilícitos (Grupo de Memoria Histórica [GMH], 2013).

En el periodo 2005 - 2012, se aumenta la ofensiva militar hacia los grupos armados y por ende se vislumbra un marcado debilitamiento de las FARC-EP obligándolos a reorganizarse militarmente y la desmovilización de varios frentes paramilitares con más de 31000 combatientes (Grupo de Memoria Histórica [GMH], 2013).

A mediados del 2012 se iniciaron negociaciones con las FARC-EP. Cuatro años después de negociaciones públicas se firmó el 24 denoviembre de 2016, el Acuerdo final para la terminación del conflicto y la construcción de una paz estable y duradera, en el teatro Colón en Bogotá. (FARC -EP \& Gobierno de Colombia, 2016). Se trata del Acuerdo surgido luego del Plebiscito del 02 de octubre de 2016, luego de que el NO a la aprobación del Acuerdo inicialmente firmado en La Habana, el 24 de agosto de 2016, superara al SI, por un estrecho margen, lo que obligó a su revisión y modifi- 
cación en varios puntos, manteniendo el espíritu del Acuerdo inicial y también respondiendo a la exigencia ciudadana de no dar marcha atrás. El Acuerdo fue refrendado por el Congreso de la República en noviembre 30 de 2016.

Pensar en una Colombia en paz implica un cambio en la organización del Estado, en las ideológicas políticas, en las estructuras jurídica y en la mentalidad de los ciudadanos; es pensar en una nueva Colombia fundada en principios de justicia e inclusión, sin embargo, el dilema central de la paz se refiere a las contradicciones y retos institucionales y políticos que surgen para su aplicación cuando se combinan las expectativas y el poder diferenciado de los actores que participan en el proceso: víctimas, victimarios, gobierno, sociedad civil y comunidad internacional; con la expectativa social amplia en torno a la reconciliación nacional y se contraponen entonces un sinfín de teorías sobre lo que se entiende por paz.

La Paz en Colombia no es un acuerdo, este es solo quizás el inicio de una transformación que requiere compromiso estatal, social e individual, a lo largo de la historia los diferentes estudios que se han hecho sobre el concepto de paz han demostrado que no es un asunto exclusivo de garantías estatales, de ausencia de guerra, de no violencia, que el logro de la paz compromete además una injerencia de los valores, la cultura y el individuo.

\section{Conceptos de paz: de la Paz Perpetua a la Paz Neutra}

Una de las primeras conceptualizaciones de paz se llevó a cabo en 1713 por parte del Abbé de Saint-Pierre y se fundamenta en la preocupación profunda ante la Guerra de Sucesión Española y sus consecuencias para todas las potencias europeas que participaron en ella, cristalizando su idea en las vías alternativas que encaminaran a Europa hacia la paz, para el Abbé, esta solo era posible a través de la creación federación de Estados Europeos, construcción que desarrolló a través de un escrito conocido como Projet pour rendre la paix perpétuelle en europe (Castel de Saint-Pierre, 1713), la asociación de veinticuatro Estados necesitaría también de la creación de una institución fundamental que ostente entre sus características, la de ser un tribunal en los conflictos de los Estados asociados, mediante el cual se haga efectiva la prohibición de intervención de la federación en asuntos internos de cada Estado, proponiendo como excepción la ayuda 
contra sediciosos y rebeldes, solo de este modo era posible la Paz Perpetua (Bello, 2010).

El proyecto del Abbé de Saint-Pierre dio lugar a las propuestas de pensadores como Rousseau y Kant. El primero lo cristalizó a través de sus trabajos Projet de paix perpétuelle (Rousseau, 2012) y Jugement sur le "Projet de paix perpétuelle" de l'abbé de S.-Pierre (Rouseau, 1857), manifestaba inicialmente el apoyo para la creación de una confederación que una a los Estados europeos, y la posibilidad que esta asociación cuente con una institución que solucione los conflictos en caso de presentarse, con procedimientos preestablecidos y buscando decisiones justas, sin embargo, Rousseau critica duramente la propuesta del Abbé de Saint-Pierre por considerarla ingenua e idealista, pues no concibe que los gobernantes y políticos actúen desinteresadamente, aun cuando el fin propuesto sea la paz, para Rousseau la creación de la confederación no se daría por una situación fortuita sino que destaca la necesidad utilizar la ciencia política como herramienta que favorezca la obtención del fin deseado (Granja Castro \& Charpnel Elorduy, 2014).

El segundo, Kant (1795) sintetiza su visión de Paz Perpetua a través de una estructura organizada en seis artículos preliminares, tres artículos definitivos, uno sobre el secreto necesario para obtener la paz perpetua, una sección dedicada a las garantías que debe ofrecer la paz, y dos apéndices que plantean la relación entre moral y política.

La visión Kantiana propone comportamientos específicos tales como: el entendimiento del Estado como un sociedad de hombres que no puede ser enajenada, heredada o donada; la terminación de toda hostilidad; la disolución permanente de los ejércitos; la prohibición a la intervención en los asuntos propios de un Estado; la negativa ante la adquisición de deudas para sostener la política externa; una constitución de tinte republicano que garantice la independencia del Estado frente a la comunidad internacional y el trato hospitalario a cada ciudadano que se encuentre en el extranjero.

Una de las garantías para la consecución de su objetivo es la propia naturaleza, en la medida que utiliza en su provecho el mecanismo de las inclinaciones humanas y el sentido práctico - moral, que teóricamente sería suficiente para obligar al hombre a trabajar por conseguir ese fin; otra de las garantías al proceso estaría en la posibilidad que se le otorgue a los 
filósofos de expresarse libre y públicamente sobre las máximas generales de la guerra y la paz.

Por su parte, el siglo XIX se caracterizó por los procesos independentistas de territorios que estaban bajo el dominio europeo, los conceptos de paz conocidos surgen principalmente de líderes de movimientos de esta índole. Es así como sobresalen los legados de Simón Bolívar y Mahatma Gandhi.

María Gabriela Mata Carnevali (2010), destaca como fundamental en el pensamiento del hindú la palabra Ahimsa, traducida como la no-violen- cia absoluta. Mata Carnevali utiliza como referente a:

Arun Gandhi, nieto del líder independentista, y explica que, la paz de Gandhi implicaría Amar a todos sin excepción, incluso al enemigo. La No-violencia no consiste en amar a los que nos aman. La No-violencia comienza a partir del instante que amamos a los que nos odian... Y es que para él era imposible dividir a los hombres en "buenos" o "malos" pues todos en su opinión, por naturaleza, tienen un núcleo de decencia. Lo que hay es que buscar la forma de despertarla cuando está dormida (Mata Carnevali, 2010).

Franz J. T. Lee (2010) contrasta los ideales de Bolívar y Ghandi y encuentra como puntos comunes una motivación: el colonialismo al que eran sometidos sus pueblos. Por un lado, destaca en Gandhi la responsabilidad social y el pensamiento ético. Así mismo, menciona la concepción política de Gandhi, carente de un análisis extenso, pues se limitaba a aseverar que la prioridad deberían ser los individuos, y que el Estado debe servir a sus intereses y menciona la relevancia que posee la moral en el pensamiento Gandhiano, afirmando que gracias a este las quimeras religiosas han pasado a un segundo plano.

En lo que a Bolívar respecta, Lee explica que sus tesis, profundamente inspiradas por la Ilustración y las ideas revolucionarias francesas, abogaban por la obtención de la paz incluso al margen de las leyes.

La humanidad presenció con la entrada del siglo pasado una de las épocas más violentas de la edad contemporánea. Recibió este periodo con la 
denominada Gran Guerra, la consecuente depresión económica y posteriormente, como si no hubiese aprendido la lección, una Segunda Guerra Mundial. Estos nuevos escenarios ayudaron al nacimiento de líderes sociales y políticos que inspirados en actores como Gandhi, aunaron por la construcción de un concepto de paz a partir de la desobediencia civil, la no-violencia y la lucha pacífica.

Con el estallido de la Segunda Guerra Mundial se vislumbró la utopía característica de las concepciones, y los teóricos empezaron a contemplar la política internacional mediante una forma más realista, lo que significó que la prevención de las guerras dejara de ser solamente una cuestión reglamentaria para los Estados, e involucrara directamente a la población civil, reorientando su actitud en dicho sentido. Posterior en las décadas de 1960 a 1980 -que fueron decisivas en la actualización del derecho internacional público-, los estudios de paz se centraron en el internacionalismo, la democratización de la política exterior y la actualización de los portavoces no oficiales y, además, se le dio mayor importancia al estudio de la forma más apropiada de tomar decisiones en caso de afrontar una crisis internacional.

Aproximadamente en la década de los 70 se inicia un nuevo ciclo para estos estudios, se pasa de una investigación convencional a una con espíritu crítico, generando un cambio en el entendimiento de los términos de conflicto, violencia y paz lo que brindó la dimensión critica del ciclo y creo la diferencia substancial con respecto a los anteriores estudios, gracias a esto se inició un significativo interés en factores que generen las condiciones para garantizar la paz mundial.

La esperanza de una paz perpetua se había visto opacada por la lucha de intereses propia del ser humano, por lo que se retomó el concepto de No Violencia como sinónimo de paz. Galtung (1965), se plantea las dificultades de la construcción de este concepto, algunas veces asimilable a conductas positivas por parte de los sujetos y en otras ocasiones, como sinónimo simple de no agresión; identifica los tipos de violencia y se refiere a la paz negativa-ausencia de guerra-, y a la pazpositiva-estado de cooperación. 
Galtung (1996) construye dos definiciones compatibles: Paz como "abstención o reducción de violencia de todo tipo"; paz como no violencia y transformación creativa de conflictos. Uno de sus principales aportes ha sido considerar el conflicto como elemento necesario para la evolución del ser humano, y no como generador de violencia en sí mismo. ${ }^{4}$

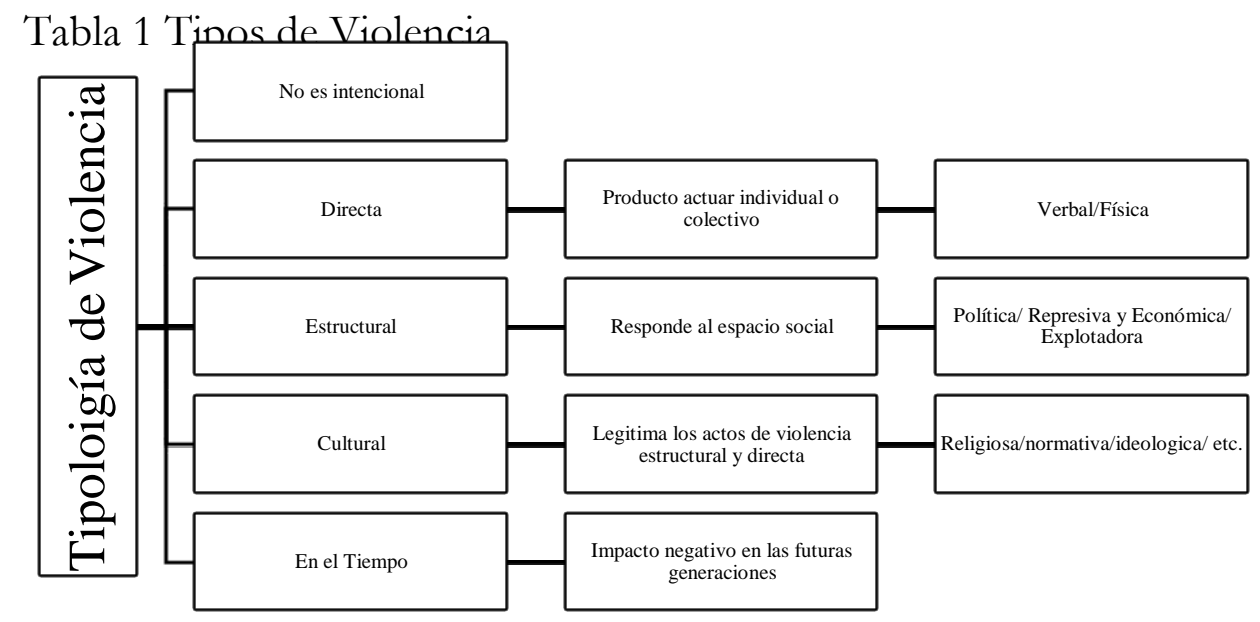

Fuente: Creación del autor a partir de (Galtung, Peace by Peaceful Means. Peace and Conflict, Development and civilizations, 1996)

En palabras de Vicente Hueso (2000), la paz construida por Galtung reconoce lo incierto de la violencia, y la dificultad que entraña una cultura pacifista debido a la tentación de institucionalizarla, volviéndola obligatoria y alejándola de la realidad.

Referirse únicamente a la paz negativa como la ausencia de violencia de todo tipo, ignora voluntariamente la existencia de la violencia estructural y la cultural, negando una de las características principales del ser humano -la necesidad de vivir en sociedad-convirtiendo la paz en un concepto

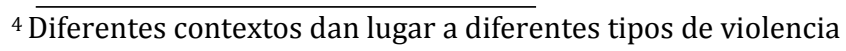


estático. En respuesta a esto, Galtung (1996) plantea una tipología de paz positiva, que responde a un escenario integral de las relaciones humanas:

Tabla 2 Tipología de paz positiva.

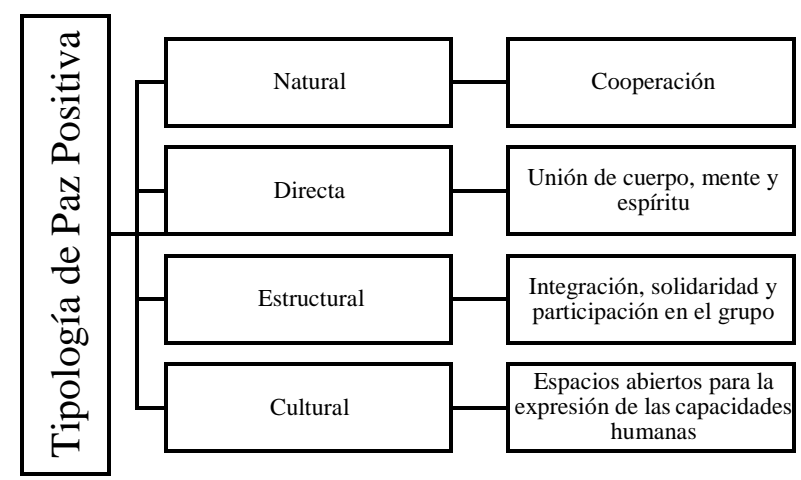

Fuente: Creación del autor a partir de (Galtung, Peace by Peaceful Means. Peace and Conflict, Development and civilizations, 1996)

En una revisión a los conceptos de violencia cultural, estructural y directa, lleva a Galtung a la idea de paz cultural, como fuente esencial de paz estructural y directa, expresa que lo contrario a la paz es la violencia, no el conflicto, dando la oportunidad de manejar conflictos a través de la empatía, no-violencia y creatividad,

Este sistema triangular de la violencia debe ser contrastado mentalmente con uno similar para la paz, en el que la paz cultural engendre la paz estructural, lo que se traduce en relaciones simbióticas, equitativas entre los diversos socios; y la paz directa se manifieste en actos de cooperación, amistad y amor (Galtung, 2016).

Paris Varvarousis (1996) desarrolla un estudio histórico del concepto de paz, reconociendo que el mismo se fundó en un pensamiento racionalista y un criterio de conveniencia, influenciado por la política, para reconocer el fenómeno bélico como algo natural, pero estos fundamentos nunca lograron crear cimientos para una paz perdurable. 
El tema de la paz se desborda en distintos ámbitos, por ejemplo, se puede estudiar mediante el socialismo a través de los planteamientos de Marx, Engels y Lenin, quienes afirmaron que se trata de fenómenos determinados por la lucha de las clases y que la reforma social puede garantizar el afianzamiento definitivo de la paz; a través del psicoanálisis de Freud, para quien el hombre se encuentra entre dos tendencias primarias: el anhelo de alcanzar la felicidad, un impulso de vivir o libido, el cual es realizable por la procreación, y una tendencia hacia la destrucción, un instinto de muerte, que va aumentando por las circunstancias que las guerras y la barbarie provocan.

Siguiendo esta misma línea, Vivenc Fisas (1998) plantea la cultura de paz, que solo es posible con la implemntacion de un sistema de educación para la paz, que incia reconociendo en el ser humano conductas violentas producto de las relaciones sociales, la crianza y el entorno, por lo que el camino hacia su consolidación debe estar dirigido a desacreditar todas aquellas conductas que legitimizan el uso de la fuerza. En este aspecto la Educación para la paz busca aportar la información que permita interpretar la realidad a traves de las variables correctas; fomentar la participacion ciudadana en los cambios estructurales dentro de la política y la economia; reconocer los intereses del oponente, no como el enemigo, sino como un igual; y finalmente, llevar a cabo un desarme cultural por parte de los pueblos dominantes, aceptando la diversidad cultural humana y la riqueza inmaterial que ésta representa.

Por otro lado, Muñoz (2001) se niega a entender la paz como realidad absoluta, y decide denominarla como imperfecta, pues es un proceso vivo y activo que se encuentra relacionado con las acciones de los seres humanos, sus decisiones y preferencias. La paz o la violencia emergen por decisión del hombre, quienes determinan con sus acciones y omisiones la existencia de más paz o más violencia.

La paz evoluciona con las necesidades humanas, absorbiendo de alguna forma las políticas predominantes en cada contexto, en este sentido Oscar Mateos Martín (2011) concibe La Paz Liberal, de la cual se desprenden pensamientos y formas de paz contradictorias pero a la vez complementarias: i) la paz del vencedor, basado en la victoria militar; ii) la paz constitucional - institucional, descansa sobre la idea de aferrar al Estado a un 
orden democrático liberal, fomentando la democracia, el libre comercio, y un conjunto de valores cosmopolitas; y iii) la paz civil, que no desautoriza la anterior, sino que sitúa el foco en el individuo trascendiendo el enfoque marcadamente estado-céntrico de las anteriores.

El concepto de Paz Neutra, inicialmente desarrollado por Francisco Jiménez Bautista (2014), como un método para eliminar la violencia cultural y/o simbólica a través del diálogo, el cual permite la deconstrucción de las ideas y juicios preconcebidos con los cuales estamos programados todos los seres humanos y que nos impiden ser verdaderamente imparciales frente a otros, como un concepto utópico fuera del alcance de la visión parcializada del ser humano, lo que no limita su ámbito de acción, pues se considera el ideal al que deben apuntar todas las sociedades con el fin de mejorar las relaciones intra e intersociales.

La neutralidad debe entenderse como la "base de toda relación social ya que con el respeto al «otro» se desvalorizan las distintas formas de violencia (directa, estructural y cultural y/o simbólica)" (Jimenez Bautista, 2014), en este punto, el citado autor propone 'verbalizar' el sustantivo, es decir, neutralizar los espacios de violencia cultural y/o simbólica que existen dentro de una sociedad, a través de la comprensión de principios y valores. Lo anterior no significa, eliminar aquellos elementos que hacen un colectivo diferente de otro creando un mundo insensible, estoico y uniforme, sino por el contrario, adquirir nuevas formas de pensamiento que deprecien la violencia cultural y/o simbólica.

La materialización de la Paz Neutral se logra a través del diálogo, a través de la comunicación como fuente del entendimiento, por lo tanto, la paz neutral, demanda un cambio estructural social profundo que solo podrá alcanzarse a través del abandono de la estigmatización del otro por prejuicios intrínsecos en cada ser humano, además exige anteponer la comprensión del «otro» como requisito para la producción de conocimiento, transformando los métodos preestablecidos para conocer e interpretar la realidad y crear lo que se denomina "la construcción de un paradigma pacífico" (Jimenez Bautista, 2014).

Por consiguiente, si se analiza el discurso de paz planteado a lo largo del proceso de terminación del conflicto con las FARC EP claramente se 
acerca a lo esbozado por Jiménez Bautista (2014) en la Paz Neutra cuando se manifiesta dentro de las Mesas de Conversaciones que:

La nueva visión de una Colombia en paz permita alcanzar una sociedad sostenible, unida en la diversidad, fundada no solo en el culto de los derechos humanos sino en la tolerancia mutua, enla protección del medio ambiente, en el respeto a la naturaleza, sus recursos renovables y no renovables y su biodiversidad [...] (2016)

Y por ende, una paz estable y duradera solo es posible a través del fin del conflicto armado, la reparación de las víctimas, la integración de todas las zonas del territorio nacional, la inclusión social y el fortalecimiento de la democracia, con el objetivo de construir una cultura de tolerancia, respeto, y convivencia general, con un enfoque regional que reconoce necesidades distintas en cada uno de los sectores afectados por los más de cincuenta años de guerra.

\section{Concepto de paz desde la jurisprudencia}

La Corte Constitucional fue creada por la Constitución Política de 1991, como un órgano integrante de la rama judicial, según la teoría de la tridi- visión de poderes adoptada por el Estado colombiano. Este órgano es el encargado de la guarda de la integridad y supremacía de la constitución, así mismo, posee funciones específicas consagradas en el artículo 241 su- perior, entre las que se encuentra la revisión de la constitucionalidad de las normas del expedidas en ejercicio del poder legislativo, sea por vicios de forma o de fondo, ya sea a solicitud de un interesado -mediante de- mandas- o, determinarla de oficio cuando le es permitido; es así como en cumplimiento de sus funciones, la misma corporación ha dicho que "entre la Constitución y la Corte Constitucional, cuando ésta interpreta aquélla, no puede interponerse ni una hoja de papel” (Sentencia C 113, 1993).

La posición garantista asumida desde el principio por este Alto Tribunal ha propendido por la protección de los derechos, deberes y principios consagrados en la Carta Política, por lo que la paz no ha escapado de su esfera de interpretación. El artículo 22 de la Constitución, denomina la paz 
como un derecho y deber de obligatorio cumplimiento, por lo que estos conceptos serán fundamentales en la organización y funcionamiento del Estado, en este sentido, la Corte Constitucional ha dedicado tiempo a la elaboración de una línea jurisprudencial, en virtud de los acontecimientos que dictan la realidad social del país, principalmente el conflicto armado.

Mediante la sentencia T- 06 de 1992 se adoptó un concepto de paz enmarcado en la seguridad jurídica, pues se debatía la procedencia de la tutela en contra de sentencias judiciales, en este caso se entendió la paz como la garantía de derechos que deben ser protegidos por parte del gobierno y que, complementada con los derechos humanos, debe considerarse la columna vertebral de la democracia. En el mismo año, en sentencia T- 08, 1992, se le denomina por primera vez como un derecho de tercera generación - Derecho Colectivo-, y en el año siguiente, en la sentencia T102 de 1993, se considera un derecho autónomo que envuelve un poder que emana de los particulares y les concede la posibilidad de exigirle al Estado la exclusión de la violencia dentro de la comunidad, manifestándose como un derecho colectivo, un derecho individual y un deber del ciudadano:

Es un derecho de autonomía en cuanto está vedado a la injerencia del poder público y de los particulares, que reclama a su vez un deber jurídico correlativo de abstención; un derecho departicipación, en el sentido de que está facultado su titular para intervenir en los asuntos públicos como miembro activo de la comunidad política; un poder de exigencia frente al Estado y los particulares para reclamar el cumplimiento de obligaciones de hacer. Como derecho que pertenece a toda persona, implica para cada miembro de la comunidad, entre otros derechos, el de vivir en una sociedad que excluya la violencia como medio de solución de conflictos, el de impedir o denunciar la ejecución de hechos violatorios de los derechos humanos y el de estar protegido contra todo acto de arbitrariedad, violencia o terrorismo (Sentencia $\mathrm{T}$ 102, 1993). 
Desde 1993 hasta el año 2001 no hubo pronunciamientos relevantes con respecto a la definición de la Paz como derecho. No fue sino hasta la sen- tencia C- 048 de 2001 que se le reconoce un triple carácter constitucional: la consideró un valor de la sociedad, fundamento del Estado y de los de- rechos humanos (preámbulo); un fin esencial que irradia el ordenamiento jurídico y que, como principio, debe dirigir la acción de las autoridades públicas (art. 2), y finalmente, también la entiende como un derecho cons- titucional (art. 22).

Mediante sentencia C- 578 de 2002, en el estudio de constitucionalidad de la Ley 742 de 2002 -por medio de la cual se adoptaba el Estatuto de Roma de la Corte Penal Internacional-la Corte Constitucional consideró que la paz ocupaba un lugar principal en el orden de valores que contempla la Constitución, pues "[...]Dentro del espíritu de que la Carta Política tuviera la vocación de ser un tratado de paz, la Asamblea Constituyente protegió el valor de la paz de diferentes maneras en varias disposiciones [...]".

La Corte Constitucional en la sentencia C- 1153 de 2005, en control de constitucionalidad de la Ley 966 del 24 de noviembre de 2005 de Garantías Electorales vuelve a traer a colación la definición de Paz, y le adicionara, además de las características anteriormente mencionadas, un tinte político, considerándola como el respeto a la pluralidad de ideas y proyectos políticos.

En el estudio de constitucionalidad de la Ley de Justicia y Paz -Ley 975 de 2005- por medio de la sentencia C 370 de 2006, los magistrados definen el concepto de paz como un derecho y propósito fundamental de la comunidad internacional, y como un derecho colectivo en cabeza de la humanidad, la cual debe propender a su logro y mantenimiento.

La sentencia C- 784 de 2014, en virtud del control constitucionalautomático de leyes estatutarias, se analizó el proyecto de ley que dictaba reglas para el desarrollo del referendo con ocasión de acuerdo final para la terminación del conflicto armado, en el cual se consideró la paz como la libertad en el actuar y pensar de individuos y grupos, eliminando elementos que puedan coaccionar o amenazar dichas libertades, siendo estas, las mismas condiciones para una democracia plena.

Y en el desarrollo del control constitucional del proyecto de ley estatutaria que regula el plebiscito para la refrendación del acuerdo final para 
la terminación del conflicto y la construcción de una paz estable y duradera, se resume la posición de la Corte en la sentencia C- 379 de 2016, y se analiza el derecho a la paz, consagrado desde el bloque de constitucionalidad -Derecho Internacional Público- como aquel mediante el cual se hace un reconocimiento intrínseco a la dignidad humana y se vincula su efectividad como obligación fundamental de todo Estado y requisito para la promoción y protección de los derechos humanos.

Tabla 3 Evolución jurisprudencial del concepto de paz.

\begin{tabular}{|c|c|}
\hline Sentencia T 06/1992 & $\begin{array}{l}\text { - PAZ = Seguridad jurídica (Garantía de la } \\
\text { democracia + Derechos humanos) }\end{array}$ \\
\hline Sentencia T 08/1992 & - $\mathrm{PAZ}=$ Derecho Colectivo \\
\hline Sentencia T 102/1993 & $\begin{array}{l}\text { - PAZ = Derecho Autónomo (Derecho Colectivo } \\
\text { + Derecho individual + Deber del ciudadano) }\end{array}$ \\
\hline Sentencia C 048/2001 & $\begin{array}{l}\cdot \text { PAZ }=\text { Valor de la sociedad }+ \text { Fin esencial del } \\
\text { Estado + Derecho Constitucional }\end{array}$ \\
\hline Sentencia C 378/2002 & - $\mathrm{PAZ}=$ Valor Prioritario del Estado \\
\hline Sentencia C 1153/2005 & $\begin{array}{l}- \text { PAZ = Seguridad Jurídica + Derecho Autónomo + Valor } \\
\text { Prioritario del Estado + Fin esencial del Estado + Derecho } \\
\text { Constitucional + Pluralidad de ideas + Proyectos Políticos }\end{array}$ \\
\hline Sentencia C 370/2006 & $\begin{array}{l}\text { PAZ = Derecho y propósito fundamental de la } \\
\text { comunidad internacional+ un derecho colectivo en } \\
\text { cabeza de la humanidad }\end{array}$ \\
\hline Sentencia C 784/2014 & $\begin{array}{l}\text { - PAZ = Democracia plena (libertad en el actuar y } \\
\text { pensar de individuos y grupos) }\end{array}$ \\
\hline Sentencia C379/2016 & $\begin{array}{l}\cdot \text { PAZ }=\text { Bloque de constitucionalidad (Reconocimiento } \\
\text { intrínseco a la dignidad humana + obligación } \\
\text { fundamental del Estado + Derechos humanos) }\end{array}$ \\
\hline
\end{tabular}

Fuente: Creación del autor 
La Corte Constitucional ha estudiado el concepto de paz, partiendo de las definiciones más básicas, y posteriormente, agregándole elementos nece- sarios para responder a las circunstancias vivenciadas en el territorio na- cional; en cumplimiento de la función interpretativa de la Constitución y de la voluntad de la Asamblea Nacional Constituyente, ha ampliado el ámbito de aplicación hasta entender la paz como fundamento integrador.

\section{Conclusiones}

La población Colombiana se ha acercado al concepto de paz por los he- chos violentos y derivados de los conflictos con diversos grupos insurgen- tes, por lo cual su concepción no puede ser enmarcada dentro los diferen- tes conceptos de paz en donde sus autores partían de los conflictos neta- mente entre estados, es solo hasta Ghandi que se empieza a hablar de la paz desde la cultura y la naturaleza humana.

El concepto de paz al ser analizado desde su contexto, las particularidades de los territorios y los individuos debe ser entendido: como una obligación y fin del Estado, como un derecho constitucional y como el respeto a la dignidad humana de cada uno de los miembros del mismo.

Este concepto se vuelve tangible si los estados dentro de sus instituciones propenden por un dialogo que permita una comunicación que dé lugar a pensar en el otro y entenderlo, para así construir un respeto y una tolerancia, que lugar que dé lugar a que los conflictos no deriven en violencia.

\section{Referencias bibliográficas}

Arias, M. A., Camacho, A., Ibañez, A. M., Mejia, D., \& Rodríguez, C. (2014). Costos Económicos y Sociales del Conflicto en Colombia; ¿Cómo construir un posconflicto sostenible? Bogotá, Colombia: Ediciones Uniandes.

Bello, E. (2010). La construcción de paz: El proyecto de Abbé de Saint -Pierre. Res Publica, 121-135.

Castel de Saint-Pierre, C.-I. (1713). Source gallica.bnf.fr. Obtenido de Bibliothèque nationale de France: https://upload.wikimedia.org/wikipedia/commons/c/c2/Saint-Pierre_- 
_Projet_pour_rendre_la_paix_perp\% $\%$ C3\%A9tuelle_en_Europe__Tome_2\%2C_1713.pdf

FARC -EP \& Gobierno de Colombia. (24 de Noviembre de 2016). Acuerdo Final para la Terminación del Conflicto y la Construcción de una Paz Estable y Duradera.

Obtenido de http://www.altocomisionadoparalapaz.gov.co/procesos-yconversaciones/Documentos $\% 20$ compartidos/24-11-

2016NuevoAcuerdoFinal.pdf

Fisas, V. (1998). Una cultura de paz. En V. Fisas, Cultura de pazy gestión de conflictos. Barcelona: Icaria/NESCO.

Galtung, J. (1965). On the meaning of nonviolence. Journal of Peace Research, 288256.

Galtung, J. (1996). Peace by Peaceful Means. Peace and Conflict, Development and civilizations. Londres: SAGE Publications Ltd.

Galtung, J. (2016). La violencia: cultural, estructural y directa. Cuadernos de Estrategias, 147-168.

Gobierno de Colombia \& FARC-EP. (26 de Agosto de 2012). Mesa de Conversación.

Obtenido

https://www.mesadeconversaciones.com.co/sites/default/files/AcuerdoG eneralTerminacionConflicto.pdf

Gómez Araújo, L. A. (2002). Reflexiones acerca de los procesos de paz en Colombia. Marco jurídico y otras consideraciones. Revista de Derecho. Universidad del norte, 118-134.

Granja Castro, D., \& Charpnel Elorduy, E. (2014). El ideal de la Paz Perpetua en Rousseau y Kant. Signos Filosóficos, 37-62.

Grupo de Memoria Historica [GMH]. (2013). ¡BASTA Y A! Colombia: Memorias de guerra y dignidad. Bogotá D.C., Colombia: Imprenta Nacional.

Hueso Garcia, V. (2000).

Jimenez Bautista, F. (2014). Paz neutra: Una ilustración del concepto. Revista de Pazy Conflictos, 19-52.

Kant, I. (1795). Sobre la pazperpetua. Madrid: Akal.

Lee, F. J. (2010). El significado revolucionario contemporáneo de Mahatma Gandhi y Simón Bolívar para la emancipación humana. En H. Lucena Morelo, Simón Bolivar y Mabatma Gandhi: Paradigmas liberadores (págs. 261-275). Universidad de Los Andes. 
Lopez de la Roche, F. (2015). El Gobierno de Juan Manuel Santos 2010 -2015: Cambios en el Régimen Comunicativo, Protesta Social y Proceso de Paz con las FARC. Análisis Politico No. 85, 3-37.

Martín Marcos, D. (2011). El Papado y la Guerra de Sucesión española. Madrid: Marcial Pons, Ediciones de Historia S.A.

Mata Carnevali, M. (2010). La Paz en Gandhi. En H. Lucena Morelo , Simón Bolivary Mahatma Gandhi: Paradigmas liberadores (págs. 181-192). Universidad de Los Andes .

Mateos M., O. (2011). La Construcción de Paz Posbélica.Análisis de los Debates Críticos a través del caso de Sierra Leona. Tesis Doctoral. Universitat Autónoma de Barcelona (UAB).

Mendoza Ramos, L. (2015). Conflicto y Paz en Colombia: Una perspectiva desde los indicadores sociales. Palobra, 190-212.

Mesa de Conversaciones. (24 de Noviembre de 2016). Acuerdo final para la terminación del conflicto y la construcción de una paz estable y duradera. La Habana, Cuba.

Muñoz, F. A. (2001). La Paz. Imperfecta Ante un Universo en Conflicto. Obtenido de Universidad de Granada: http://www.ugr.es/ eirene/eirene/Imperfecta.pdf

Muñoz, F., \& López Martínez, M. (2004). Historia de la Paz. En F. A. Muñoz, Manual de paz y Conflictos. Granada: UNIVERSIDAD DE GRANADA. Obtenido de Historia de la Paz.

Parra Dussan , C., \& Herrera Nossa, C. (2016). Instrumentos Jurídicos del Proceso de Paz. Revista de Derecho, Universidad del Norte, 111-136.

Ramos M., E. A. (2016). El Proceso de Construcción de Paz Colombiano Más Allá De La Negociación: Una Propuesta desde La Paz Transformadora y Participativa. AGO.USB, 513-532.

Rodriguez Pico, C. R. (2015). Participación Politica en los Acuerdo de Paz de la Habana: El Prerreuisito de la Refrendación de los acuerdos. Análisis Político N. $85,57-75$.

Rouseau, J.-J. (1857). Jugement sur le "Projet de paix perpétuelle" de l'abbé de S.-Pierre. Obtenido de http://gallica.bnf.fr/ark:/12148/bpt6k57875906

Rousseau, J.-J. (7 de Octubre de 2012). Projet de paix prpétuelle. Obtenido de Collection complète des oeuvres, Genève, 1780-1789, vol. 12, in- $4^{\circ}$,: https://www.rousseauonline.ch/pdf/rousseauonline-0082.pdf

Sentencia C 048, M.P. Dr. Eduardo Montealegre Lynett (Corte Constitucional 24 de Enero de 2001). 
Sentencia C 113, M.P. Jorge Arango Mejia (Corte Constitucional 25 de Marzo de 1993).

Sentencia C 1153, M.P. Dr. Marco Gerardo Monroy Cabra (Corte Constitucional 11 de Noviembre de 2005).

Sentencia C 370, M.P. Dr. Manuel José Cepeda Espinosa, Dr. Jaime Córdoba Triviño, Dr. Rodrigo Escobar Gil (Corte Constitucional 18 de Mayo de 2006). Sentencia C 379, M.P. Dr. Luis Ernesto Vargas Silva (Corte Constitucional 18 de Julio de 2016).

Sentencia C 578, M.P. Dr. Manuel José Cepeda Espinosa (Corte Constitucional 30 de Julio de 2002).

Sentencia C 784, M.P. Dra María Victoria Calle Correa (Corte Constitucional 21 de Octubre de 2014).

Sentencia T 06, M.P. Dr. Eduardo Cifuentes Muñoz (Corte Constitucional 12 de Mayo de 1992).

Sentencia T 08, M.P. Dr. SIimon Rodriguez Rodriguez Dr. Jaime Sanin Greiffenstein (Corte Constitucional 22 de Enero de 1992).

Sentencia T 102, M.P. Dr. Carlos Gaviria Diaz (Corte Constitucional 10 de Marzo de 1993).

Varvarousis, P. (1996). La Idea de la Paz: Bogotá D.C: Editorial Temis S.A. 